\title{
RETICENCIAS E INEXACTITUDES \\ EN EL CONTRATO DE SEGURO: \\ BREVE COMPARACIÓN A LA JURISPRUDENCIA \\ DE LA CORTE SUPREMA DE JUSTICIA \\ Y LA SUPERINTENDENCIA FINANCIERA
}

\section{RELUCTANCE AND INACCURACIES IN THE INSURANCE CONTRACT: BRIEF COMPARISON OF THE JURISPRUDENCE OF THE SUPREME COURT OF JUSTICE AND THE FINANCIAL SUPERINTENDENCE OF COLOMBIA}

\author{
DAVID AUGUSTO TEJEIRO CARRILLO** \\ Fecha de recepción: 30 de noviembre2019 \\ Fecha de aceptación: 15 de diciembre2019 \\ Disponible en línea: 30 de diciembre 2019
}

Para citar este artículo/To cite this article

Tejeiro Carrillo, David Augusto, Reticencias e inexactitudes en el contrato de seguro: breve comparación a la jurisprudencia de la Corte Suprema de Justicia y la Superintendencia Financiera, 51 Rev.Ibero-Latinoam.Seguros, 217-240 (2019). https://doi.org/10.11144/Javeriana. ris51.rics

doi:10.11144/Javeriana.ris51.rics

\footnotetext{
Trabajo de investigación presentado para optar al título de especialista en derecho de seguros.

** Abogado graduado con mención meritoria de la Universidad del Rosario. Especialista en Derecho de Seguros de la Universidad Javeriana, candidato a Magister en Derecho Administrativo de la misma universidad y Magister en Argumentación Jurídica de la Universidad de Alicante en convenio con la Universidad de Palermo. Contacto: datc19@hotmail.com. https:// orcid.org/0000-0003-2663-7336
} 


\section{RESUMEN}

Con ocasión de la atribución de funciones jurisdiccionales a la Superintendencia Financiera de Colombia, se ha dado paso a la creación de una jurisdicción especializada en materias cuyo juez natural, dentro de la justicia ordinaria, no conocía, aparentemente, a profundidad, y, en esa medida, generaba desconfianza en los distintos sectores expuestos a sus decisiones.

Transcurridos más de cinco años desde la entrada en vigencia de la Ley 1480 de 2011, que, en su artículo 57, introdujo esta facultad en la Superintendencia, se procederá a establecer las distintas posiciones adoptadas por el juez ordinario (Corte Suprema de Justicia - Sala de Casación Civil) y el juez especializado, en lo relacionado al contrato de seguro, y más específicamente, en lo referente a las reticencias e inexactitudes que de éste se desprenden.

Palabras Clave: Reticencia, Inexactitud, Declaración del Estado del Riesgo, Verificación de la Información Declarada, Mala fe, Carga de la Prueba, Deber de Información. 


\begin{abstract}
On the occasion of the attribution of jurisdictional functions to the Financial Superintendence of Colombia, a specialized jurisdiction has been created in matters whose natural judge, apparently, did not resolve in depth, which generated distrust in the sectors exposed to their decisions.

After more than seven years of entry into enforcement of Law 1480 of 2011 that in its Article 57 created that mission in the Superintendence, it will be shown the positions adopted by the Supreme Court of Colombia and the specialized judge (Financial Superintendence of Colombia), related to the insurance contract, more specifically in relation to false declarations and inaccuracies.
\end{abstract}

Keywords: False declarations, Inaccuracies, Declaration of the state of the risk, Verification of the declared information, Bad faith, Burden of the proof, Information duty.

\title{
SUMARIO
}

INTRODUCCIÓN. 1. SITUACIONES DERIVADAS DEL CONOCIMIENTO O DESCONOCIMIENTO DEL RIESGO POR PARTE DEL ASEGURADOR. 1.1. Obligatoriedad del tomador/asegurado de declarar el estado del riesgo frente a la no presentación de un cuestionario por parte del asegurador. 1.2. Alcance del conocimiento presuntivo del asegurador derivado de las inspecciones del riesgo. 1.2.1. Saneamiento de la reticencia o inexactitud derivado de la práctica de exámenes médicos. 2. RELEVANCIA DE LAS CAUSAS Y MOTIVOS POR LOS CUALES UN TOMADOR/ ASEGURADO INCURRE EN RETICENCIA O INEXACTITUD, AL MOMENTO DE APLICAR LAS SANCIONES DERIVADAS DE DICHA CONDUCTA. 3. LA RELACIÓN DE CAUSALIDAD ENTRE LA RETICENCIA O INEXACTITUD Y EL SINIESTRO COMO ELEMENTO PARA DAR LUGAR A LAS SANCIONES CONTEMPLADAS EN EL ARTÍCULO 1058 DEL CÓDIGO DE COMERCIO. 4. OBLIGACIÓN A CARGO DEL ASEGURADOR DE VERIFICAR LA INFORMACIÓN DECLARADA POR EL TOMADOR/ ASEGURADO. 5. ALCANCES DEL DEBER DE INFORMACIÓN POR PARTE DEL ASEGURADOR AL TOMADOR/ASEGURADO RESPECTO DE LA DECLARACIÓN DEL ESTADO DEL RIESGO. 6. ACTOS QUE COMPORTAN DECLARACIONES INEXACTAS Y/O RETICENTES. 7. LA CARGA DE LA PRUEBA DE LA MALA FE EN CASOS DE RETICENCIA E INEXACTITUD. CONCLUSIONES. BIBLIOGRAFÍA. 


\section{INTRODUCCIÓN}

El presente estudio se dirige a analizar distintas circunstancias derivadas de la declaración del estado del riesgo, en el contrato de seguro, y sus consecuencias, a la luz de la interpretación dada a lo establecido en el artículo 1.058 del Código de Comercio, por parte de la Corte Suprema de Justicia y la Delegatura para Funciones Jurisdiccionales de la Superintendencia Financiera de Colombia.

Así las cosas, se busca realizar una evaluación detallada y comparativa de la jurisprudencia de las citadas corporaciones, frente a situaciones bien discriminadas en las cuales pueden observarse comportamientos por parte del tomador o asegurado (en seguros de vida), que entran a considerarse constitutivos de reticencia o inexactitud.

En virtud de lo anterior, se establecerán siete capítulos en los cuales se buscará contraponer el sentido de las decisiones tomadas por las citadas corporaciones respecto a un mismo contexto fáctico, determinando, en cada uno de ellos, una temática relacionada con las reticencias e inexactitudes en el contrato de seguro.

\section{SITUACIONES DERIVADAS DEL CONOCIMIENTO O DESCONOCIMIENTO DEL RIESGO POR PARTE DEL ASE- GURADOR}

En primer término, resulta oportuno anotar que las reticencias e inexactitudes son una aplicación del error como vicio del consentimiento dentro de la tratativa que le da el artículo $1058 \mathrm{del} \mathrm{C.Co}{ }^{1}$., que posee un ré-

1 Artículo 1.058 del Código de Comercio: El tomador está obligado a declarar sinceramente los hechos o circunstancias que determinan el estado del riesgo, según el cuestionario que le sea propuesto por el asegurador. La reticencia o la inexactitud sobre hechos o circunstancias que, conocidos por el asegurador, lo hubieren retraído de celebrar el contrato, o inducido a estipular condiciones más onerosas, producen la nulidad relativa del seguro. Si la declaración no se hace con sujeción a un cuestionario determinado, la reticencia o la inexactitud producen igual efecto si el tomador ha encubierto por culpa, hechos o circunstancias que impliquen agravación objetiva del estado del riesgo. Si la inexactitud o la reticencia provienen de error inculpable del tomador, el contrato no será nulo, pero el asegurador sólo estará obligado, en caso de siniestro, a pagar un porcentaje de la prestación asegurada equivalente al que la tarifa o la prima estipulada en el contrato represente respecto de la tarifa o la prima adecuada al verdadero estado del riesgo, excepto lo previsto en el artículo 1160.Las sanciones consagradas en este artículo no se aplican si el asegurador, antes de celebrarse el contrato, ha conocido o debido conocer los hechos o circunstancias sobre que versan los vicios de la declaración, o si, ya celebrado el contrato, se allana a subsanarlos o los acepta expresa o tácitamente. 
gimen especial debido a la naturaleza misma de este contrato, en el cual se presenta una dependencia por parte del asegurador frente a su candidato a tomador o asegurado en cuanto a la información que este último pone en conocimiento del primero las circunstancias concernientes al estado del riesgo que pretende trasladar al Asegurador.

De este modo, el deber de declarar en forma sincera y veraz el estado del riesgo tiene como propósito salvaguardar el equilibrio técnico- económico que se debe predicar entre el riesgo asegurado y la remuneración establecida a favor del Asegurador.

Así las cosas, en el presente capítulo se abordará el estudio de las controversias más frecuentes en torno a la anulación del contrato de seguro por declaraciones inexactas o reticentes imputables al tomador o asegurado.

\subsection{Obligatoriedad del tomador/asegurado de declarar el estado del riesgo frente a la no presentación de un cuestionario por parte del asegurador}

Frente a este punto, la Sala de Casación Civil de la Corte Suprema de Justicia ${ }^{2}$ respondió al interrogante según el cual se plantea lo siguiente: si el asegurador no proporciona un cuestionario al tomador o asegurado, ¿está este último obligado a declarar sincera y completamente el estado del riesgo?

Sobre el particular, la CSJ indicó que no es indispensable el cuestionario para llevar a cabo la declaración de asegurabilidad, y, por ende, la obligación de sinceridad y amplitud en la declaración por parte del tomador o asegurado se mantiene intacta. Lo anterior, basado en una interpretación literal del segundo inciso del artículo 1058 del C.Co., norma rectora de esta temática, el cual estima lo siguiente: Si la declaración no se hace con sujeción a un cuestionario determinado, la reticencia o la inexactitud producen igual efecto si el tomador ha encubierto por culpa, hechos o circunstancias que impliquen agravación objetiva del estado del riesgo.

Bajo este entendimiento, el cuestionario no es más que una herramienta para precisar el estado del riesgo y, en ningún caso, puede entenderse como un medio exonerador de responsabilidad del candidato a tomador o asegurado e declarar en forma fidedigna las circunstancias del riesgo.

2 Corte Suprema de Justicia. Sala de Casación Civil. Sentencia de 27 de julio de 1976. M.P. José María Esguerra Samper. 
Ahora bien, corresponde dilucidar el siguiente interrogante ¿es reticente el tomador o asegurado que al diligenciar el formulario excusa su falta de precisión y de verdad, en que no leyó ni entendió el mismo? $\mathrm{Al}$ respecto, la $\mathrm{SFC}^{34567}$ determinó que, efectivamente, se configura reticencia en estos casos, puesto que no debe el declarante dar informaciones con base en un formulario que no ha leído en su totalidad o que no ha entendido y, por lo tanto, corre con las consecuencias que esto genera, lo cual se acompasa con la carga de sagacidad y de información inherentes al ejercicio de la autonomía privada.

No obstante, ello, el cuestionario debe ser claro, pleno y limitativo, y sus preguntas no pueden ser muy generales o ambiguas, de modo que puedan generar confusión en el declarante, y, en esta vía, reticencias o inexactitudes en la información recibida ${ }^{8}$.

Por consiguiente, ni la ausencia de un cuestionario, ni malentenderlo o no leerlo darán lugar a sanear la reticencia o inexactitud derivada en que ha incurrido el declarante.

\subsection{Alcance del conocimiento presuntivo del asegurador derivado de las inspecciones del riesgo}

Al plantearse como problema el límite sobre el conocimiento presuntivo que debe poseer el asegurador derivado de las inspecciones que éste realice, la Sala Civil ${ }^{9}$, con ponencia de José Fernando Ramírez, advirtió

3 Superintendencia Financiera de Colombia. Delegatura para Funciones Jurisdiccionales. Sentencia de 10 de abril de 2014. Rad. 2013-0545.

4 Superintendencia Financiera de Colombia. Delegatura para Funciones Jurisdiccionales. Sentencia de 21 de abril de 2014. Rad. 2013-0542.

5 Superintendencia Financiera de Colombia. Delegatura para Funciones Jurisdiccionales. Sentencia de 28 de enero de 2014. Rad. 2013-0345.

6 Superintendencia Financiera de Colombia. Delegatura para Funciones Jurisdiccionales. Sentencia de 14 de noviembre de 2014. Rad.2014-0221.

$7 \quad$ En los casos expuestos, se estudió la procedencia de la nulidad relativa por reticencia en una póliza de vida grupo deudores. En estos, los declarantes firmaron el documento pre impreso aportado por la aseguradora, sin detenerse a leer lo que allí se indicaba; argumento usado a su favor para la defensa frente a la reticencia. En este sentido, la Superintendencia determinó que el hecho de no leer y firmar lo contentivo en la declaración de asegurabilidad no podría ser una razón válida para desvirtuar la reticencia, toda vez que al firmar el documento acepta lo plasmado en el mismo.

8 Superintendencia Financiera de Colombia. Delegatura para Funciones Jurisdiccionales. Sentencia de 27 de junio de 2013. Radicado 2012-0035

$9 \quad$ Corte Suprema de Justicia. Sala de Casación Civil. Sentencia de 19 de mayo de 1999. M.P. José Fernando Ramírez. 
que el conocimiento presuntivo del riesgo al tenor del inciso último del artículo 1058 del Código de Comercio, no puede entenderse total, porque como ya se dijo, la inspección directa del riesgo no supone el conocimiento cabal del mismo. Salvo en lo que, como indica el inciso en cuestión, conoció o debió conocer antes de celebrarse el contrato, o si, ya celebrado el contrato, se allanó a subsanarlos o los acepta expresa o tácitamente.

Vistas las cosas, resulta imperioso determinar cuándo el asegurador conoce o debe conocer el riesgo al que se expone. Para esto, la Corte, dentro del mismo fallo antes citado, señaló que la inspección supone el conocimiento de todas aquellas circunstancias que un asegurador diligente habría percibido con las inspecciones, o reconocimientos hechos en el caso concreto. Así, un examen médico efectuado por el asegurador durante el trámite de una solicitud de seguro de vida, conlleva el conocimiento de toda la información que razonablemente se obtiene con ese tipo de examen, no con otros. (Subrayado fuera de texto).

Por ende, la aseguradora encuentra como límite de su conocimiento presuntivo, lo que debería conocer en escenarios normales en los que se realicen las inspecciones que ésta lleve a cabo. Concluyendo así, que de existir reticencias o inexactitudes que lo hubiesen hecho contratar de una manera distinta, o no contratar, pero que conoció o debió conocer en virtud de la mencionada inspección, estas no podrán ser alegadas con miras a establecer la nulidad del contrato, máxime si se tiene que los dictados de la buena fe también se dirigen al Asegurador.

En este mismo sentido, la CSJ, con ponencia de Pedro LAFONT PIANETTA $^{10}$, sostuvo que en concordancia con lo descrito en la precedente providencia, la nulidad relativa derivada de las reticencias e inexactitudes no es siempre procedente, puesto que dado el carácter de profesional que posee la compañía aseguradora, es aceptable que en los casos en que por "la naturaleza del riesgo solicitado para que sea asegurado y por la información conocida y dada por el tomador, la compañía aseguradora, de acuerdo con su experiencia e iniciativa diligente, pudo y debió conocer la situación real de los riesgos y vicios de la declaración, mas sin embargo no alcanza a conocerla por su culpa, lógico es que dicha entidad corra con las consecuencias derivadas de su falta de previsión, de su negligencia para salir de la ignorancia o del error inicialmente padecido".

10 Corte Suprema de Justicia. Sala de Casación Civil. Sentencia de 18 de octubre de 1995. M.P. Pedro Lafont Pianetta. 
Esta posición, a su vez, fue reiterada en sentencia con ponencia de Carlos Ignacio JARAMILLO ${ }^{11}$, la cual analiza la procedencia de la nulidad relativa derivada de la declaración reticente o inexacta desde la óptica del asegurador negligente o culposo, denotando que éste, al momento en que conoció o debió haber conocido, saneó los posibles vicios derivados de la declaración, y desvirtuó la potencial sanción derivada del incumplimiento precontractual en cabeza del tomador. Esto, en virtud de su experticia que lo obliga a revisar a profundidad el riesgo a ser asumido cuando de éste se perciban situaciones sospechosas o anómalas de acuerdo con su experiencia.

Frente a esto, es innegable que surge una cuestión cuyo trasfondo es sumamente polémico, esto es, lo relacionado al saneamiento del dolo del asegurado reticente o inexacto por la negligencia del asegurador al momento de evaluar el riesgo. Esto se refleja a raíz de preguntarse: ¿hasta qué punto es posible que el dolo de una parte sea saneado por la negligencia o la culpa de su contraparte?

Basado en lo decidido por el Alto Tribunal, es plenamente válido un raciocinio según el cual la negligencia de la compañía, como experto en la materia, permite pasar por alto el comportamiento de quien realiza la declaración de asegurabilidad en el contrato de seguro.

En ese sentido, el profesor Andrés ORDOÑEZ ${ }^{12}$ arguye, trayendo a colación las normas del C.C., que el dolo no vicia el consentimiento cuando las dos partes incurren en él. Expresado de otro modo lo anterior, el dolo es compensable cuando proviene de ambas partes. Empero, no es admisible proceder de igual forma cuando el dolo de uno de los contratantes concurre con la culpa del otro.

En consecuencia, advierte el profesor ORDÓÑEZ que llegar al punto de sanear el dolo con la culpa, ello comportaría dotar de tutela jurídica a conductas engañosas de los tomadores que esperan escudarse en un descuido del asegurador para lucrarse injustamente.

Asimismo, José Fernando TORRES llega a concluir que a raíz de la posición adoptada por la CSJ, es posible que el "deber de informarse termine sustituyendo al deber de información"'13, y, por lo tanto, el

11 Corte Suprema de Justicia. Sala de Casación Civil. Sentencia de 2 de agosto de 2001. M.P. Carlos Ignacio Jaramillo.

12 ORDÓÑEZ, A. (2005). El tratamiento civil de la mala fe del asegurado en el contrato de seguro. Revista Mercatoria.

13 TORRES, J. F. (2003). Deberes de información en la etapa pre-contractual a cargo del asegurado y candidato a tomador. Revista Ibero-Latinoamericana de Seguros(19). 
principio de la ubérrima buena fe, tan asociado a este contrato, pase a un segundo plano.

No obstante, la línea argumentativa antes reseñada no ha sido de recibo para la jurisprudencia, cuyo hilo argumentativo se ha mantenido incólume. Basta observar, la conclusión adoptada en la sentencia de mayo de 2006 con ponencia de Silvio Fernando Trejos ${ }^{14}$.

Ahora bien, pese a no contar con pronunciamientos de la SFC sobre el tema antes esbozado, resulta oportuno introducir los puntos de discusión con la confianza que algún día se acuda a las normas civiles para precisar el alcance y efectos del artículo 1.058 del C.Co. en torno a esta polémica.

\subsubsection{Saneamiento de la reticencia o inexactitud derivado de la práctica de exámenes médicos}

Frente a los exámenes médicos, la Corte Suprema ${ }^{15}$, con ponencia de Jorge Castillo Rugeles, observó que la reticencia o inexactitud no es saneable por haberse realizado exámenes médicos y no ser determinada en los mismos, puesto que, el deber del declarante de declarar sinceramente el estado del riesgo subsiste, con el fin de salvaguardar el equilibrio en la ecuación prima-riesgo trasladado. De este modo, el examen médico es únicamente un medio para inspeccionar el estado del riesgo, pero éste no sustituye en ninguna medida la declaración del tomador o asegurado.

Al respecto, es relevante recordar lo señalado por la Corte ${ }^{16}$, en donde indicó que un examen médico efectuado por el asegurador durante el trámite de una solicitud de seguro de vida, conlleva el conocimiento de toda la información que razonablemente se obtiene con ese tipo de examen, no con otros.

Así pues, debe ser tal la precisión del examen médico que debe permitir conocer la causa de la reticencia o inexactitud para dar lugar a sanear la negligencia de quien declara. De esta forma, si se trata de un examen general, cuyo alcance no permitiese dar con el trastorno debatido, no podría considerarse posible un saneamiento en la declaración malintencionada o incompleta.

$14 \quad$ Corte Suprema de Justicia. Sala de Casación Civil. Sentencia de 14 de julio de 2006. M.P. Silvio Fernando Trejos.

15 Corte Suprema de Justicia. Sala de Casación Civil. Sentencia de 30 de noviembre de 2000. M.P. Jorge Castillo Rugeles.

16 Corte Suprema de Justicia. Sala de Casación Civil. Sentencia de 19 de mayo de 1999. M.P. José Fernando Ramírez. 
En este sentido, en sentencia proferida por la $\mathrm{SFC}^{17}$ se determinó que, en caso de no solicitarse exámenes médicos por parte de la entidad aseguradora, la sanción establecida en el artículo 1.058 resulta igualmente aplicable. Lo anterior con base en que la declaración que hace el tomador o asegurado subsiste a pesar de no contarse con exámenes médicos. Por ende, la declaración debe ser sincera y detallar el estado del riesgo en la mayor medida posible.

De lo anterior, si se observan a nivel general las dos posiciones examinadas, se concluye que la sola circunstancia del sometimiento a la práctica exámenes médicos [y, por extensión, a cualquier mecanismo de inspección del riesgo], no constituye un elemento que traslade la responsabilidad de conocer el estado del mismo a la aseguradora, salvo en los casos tratados anteriormente, en los cuales se reputa el reconocimiento presuntivo del Asegurador en torno a la entidad del riesgo que le fue trasladado.

\section{RELEVANCIA DE LAS CAUSAS Y MOTIVOS POR LOS CUALES UN TOMADOR/ ASEGURADO INCURRE EN RE- TICENCIA O INEXACTITUD, AL MOMENTO DE APLICAR LAS SANCIONES DERIVADAS DE DICHA CONDUCTA}

En este punto, se debatirá partiendo de la pregunta: ¿se deben tener en cuenta los motivos por los cuales el tomador o asegurado incurre en inexactitudes y/o reticencias, con miras a exonerarlo de las consecuencias de su actuar?

Respecto a esto, la Sala Civil ha apreciado, con ponencia de Silvio Fernando TREJOS ${ }^{18}$, donde se ha señalado que no importan, entonces, los motivos que hayan movido al tomador para comportarse sin fidelidad a la verdad, incurriendo con ello en grave deslealtad que a su vez propicia el desequilibrio económico en relación con la prestación que se pretende de la aseguradora, cuando se le ha inquirido para que dé informaciones objetivas y de suficiente entidad que le permitan a ésta medir el verdadero estado del riesgo; sea cual haya sido la razón de su proceder, con intención o con culpa, lo cierto es que la consecuencia de

17 Superintendencia Financiera de Colombia. Delegatura para Funciones Jurisdiccionales. Sentencia de 9 de enero de 2015.Radicado 2014-0698.

18 Corte Suprema de Justicia. Sala de Casación Civil. Sentencia de 24 de octubre de 2005. M.P. Silvio Fernando Trejos. 
su proceder afecta la formación del contrato de seguro, por lo que la ley impone la posibilidad de invalidarlo desde su misma raíz.

En el mismo sentido, en sentencia con ponencia de la magistrada Ruth Marina Díaz Rueda ${ }^{19}$, se resuelve que no importan los motivos que hayan movido al tomador o asegurado para faltar a la verdad en la declaración, puesto que su actuar afecta la formación del contrato de seguro, alterando las cargas económicas que de este se derivan. Por lo tanto, no es admisible analizar la subjetividad del actuar del declarante al momento de trasladar la correspondiente información al asegurador, puesto que su omisión a la verdad es objetivamente sancionada por los efectos nocivos que ésta produce.

Entonces, se observa que la posición de la CSJ, es clara al señalar que la reticencia e inexactitud se evaluara de manera objetiva, y no se tendrán en cuenta los motivos que dieron lugar a la misma. Posición que, a su vez, ha sido recogida y adoptada por la Corte Constitucional ${ }^{20}$, en sentencia cuyo contenido reproduce el extracto antes mencionado.

La SFC en uso de sus funciones jurisdiccionales ${ }^{2122}$, ha resuelto en igual sentido que la Sala Civil de la CSJ. En esta sentencia indicó que no importan los motivos por los cuales el asegurado o tomador declara en contra de la realidad, toda vez que debe salvaguardarse el equilibrio, $\mathrm{y}$, en este sentido, se debe dejar sin efecto el contrato de seguro.

Del mismo modo, esta corporación $\underline{23} \underline{24}$ determinó que el tomador o asegurado, según sea el caso, debe actuar con absoluta lealtad al declarar el estado del riesgo, de lo contrario, como es ya obvio, el contrato quedará

19 Corte Suprema de Justicia. Sala de Casación Civil. Sentencia de 1 de junio de 2007. M.P. Ruth Marina Díaz Rueda.

20 Corte Constitucional. Sentencia T-153 de 2014. M.P. Mauricio González Cuervo.

21 Superintendencia Financiera de Colombia. Delegatura para Funciones Jurisdiccionales. Sentencia de 30 de abril de 2014. Radicado 2013-0662.

22 Póliza de seguro de vida de deudores que pretendía ser afectada por la asegurada al sufrir una pérdida de capacidad laboral de $89 \%$. No obstante, la pretensión fue objetada por la aseguradora toda vez que consideraba que la asegurada fue reticente al no declarar la laringitis crónica y faringitis crónica que ésta padecía y cuyo conocimiento poseía antes de la fecha en la que realizo la declaración de asegurabilidad.

23 Superintendencia Financiera de Colombia. Delegatura para Funciones Jurisdiccionales. Sentencia de 24 de enero de 2014- Radicado 2013-0333.

24 Contrato de seguro de vida en el que, al cabo de un tiempo, la asegurada tuvo una pérdida de calidad laboral del 96\%, situación que puso en conocimiento de la aseguradora para afectar la póliza, y cuya respuesta fue la objeción de la reclamación basada en una reticencia dado el conocimiento previo de los quebrantos de salud que la misma padecía al momento de celebrar el contrato. 
viciado de nulidad relativa, sin que se admitan consideraciones externas que pretendan exculpar al declarante de su falta.

De esta manera, tanto la CSJ como la SFC son unánimes en torno a que no se deben tomar en consideración los motivos por los cuales se cae en reticencia o inexactitud, sino que por el contrario, basta su configuración para restarle validez al contrato de seguro.

\section{LA RELACIÓN DE CAUSALIDAD ENTRE LA RETICEN- CIA O INEXACTITUD Y EL SINIESTRO COMO ELEMENTO PARA DAR LUGAR A LAS SANCIONES CONTEMPLADAS EN EL ARTÍCULO 1058 DEL CÓDIGO DE COMERCIO}

En este punto, se plantea el siguiente interrogante: ¿la reticencia o inexactitud proceden únicamente cuando la distorsión con la realidad se configura en el siniestro, o, por el contrario, nacen desde el momento en que el riesgo se vio alterado a causa de dicha imprecisa o mendaz?

Frente a esto, la Corte ha señalado, a grandes rasgos, que no debe existir necesariamente una relación de causalidad entre la reticencia o inexactitud y la causa del siniestro, puesto que los dos son elementos independientes, y lo que se busca proteger con la sanción a la reticencia e inexactitud es la delimitación del riesgo asegurado. Para que, con base en esto, puedan determinarse estadísticamente la exposición al riesgo y su consecuente prima.

En relación con lo anterior, se enfatiza que en pretérita oportunidad la Corte Constitucional ${ }^{25}$ al concluir la exequibilidad del artículo 1.058 del C.Co., estableció que en atención a la naturaleza misma del negocio asegurador y ante la contratación 'en masa' de las pólizas de seguro, es imposible inspeccionar todos y cada uno de los riesgos que le pretenden ser trasladados, por tanto, cobra relevancia la información que le suministra el tomador o asegurado, la cual se erigen en su única fuente de conocimiento del riesgo, quedando a merced de la honestidad del declarante, so pena que el contrato en encuentre viciado de nulidad relativa desde el momento de su celebración.

No obstante, lo relevante en esta materia para la Corte consistió en que la sanción derivada de las reticencias o inexactitudes aplica sin importar si existe una relación de causalidad entre el siniestro acaecido y los hechos que no fueron puestos a consideración del asegurador, puesto que 
lo que se castiga es el desequilibrio contractual al cual se ve expuesta la compañía por virtud del tomador o asegurado, en incumplimiento al principio de ubérrima buena fe.

En ese sentido, la CSJ mediante sentencia con ponencia del Dr. Jorge SANTOS BALLESTEROS ${ }^{26}$, se enuncia que [la] reticencia acreditada en el proceso (...) no tiene porqué ser la causa del siniestro, dado que tal exigencia no la contempla ley-de conformidad con el artículo 1058 del Código de Comercio. (Subrayado fuera de texto).

A su vez, la sentencia de 1 de junio de 2007 resaltó que el vicio se genera independientemente de que el siniestro finalmente no se produzca como consecuencia de los hechos significativos, negados $u$ ocultados por quien tomó el seguro ${ }^{27}$.

En esta materia, la posición de la SFC guarda correspondencia con el derrotero antes expuesto, en la medida en que ha reiterado que no debe existir relación alguna entre la reticencia o inexactitud y el siniestro acaecido para castigar a quien incurrió en la primera con las sanciones que contempla la ley.

Para la $\mathrm{SFC}^{28}{ }^{29}$, así no exista relación entre los dos conceptos enunciados anteriormente, la nulidad procederá por tratarse de un vicio del consentimiento basado en el error. Asimismo, en otro pronunciamiento $^{30}$, la SFC señaló que la relación causal que importa y que, para estos efectos, debe existir, no es, como sostienen los demandantes, la que enlaza la circunstancia riesgosa omitida o alterada con la génesis del siniestro, sino la que ata el error o el dolo con el consentimiento del asegurador.

26 Corte Suprema de Justicia. Sala de Casación Civil. Sentencia de 11 de abril de 2002. M.P. Jorge Santos Ballesteros.

27 Corte Suprema de Justicia. Sala de Casación Civil. Sentencia de 1 de junio de 2007. M.P. Ruth Marina Díaz Rueda.

28 Superintendencia Financiera de Colombia. Delegatura para Funciones Jurisdiccionales. Sentencia de 11 de junio de 2014. Radicado 2013-0800.

29 Póliza de seguro de vida de deudores cuya reclamación se realiza por parte de la cónyuge del asegurado por la muerte del mismo. La aseguradora objeta la reclamación dado que el asegurado no declaró que padecía de hipertensión arterial y dicha enfermedad no fue puesta en conocimiento de la aseguradora al momento de realizar la declaración de asegurabilidad. Por su parte, la cónyuge sostiene que la muerte del asegurado no fue producto de la hipertensión, y, por ende, no es procedente la declaración de nulidad derivada de la reticencia.

30 Superintendencia Financiera de Colombia. Delegatura para Funciones Jurisdiccionales. Sentencia de 17 de enero de 2014. Radicado 2013-0372. 
En concordancia con esto, la Delegatura concluyó con que lo que busca la norma es restablecer el equilibrio del contrato al momento en que fue celebrado, pues, es desde este momento en que nace el vicio proveniente del error, y no cuando ocurre el siniestro ${ }^{31}$. En idéntico sentido, pueden consultarse las sentencias proferidas dentro de los procesos 2014$0082^{32}$ y 2015-2221, providencias en las cuales se sostiene la opinión que se ha venido desarrollando; confirmando así, sin ninguna novedad, lo explicado anteriormente.

\section{OBLIGACIÓN A CARGO DEL ASEGURADOR DE VERI- FICAR LA INFORMACIÓN DECLARADA POR EL TOMA- DOR/ASEGURADO}

En tratándose de la verificación que eventualmente realiza el asegurador de la información aportada por el declarante, surge el siguiente cuestionamiento: ¿el asegurador está o no en la obligación de verificar la información propuesta por quien declara el estado del riesgo?

$\mathrm{Al}$ respecto, la $\mathrm{CSJ}$ ha determinado que encontrándose probadas las reticencias e inexactitudes debe entenderse que procede la sanción prevista para esto, sin detenerse a examinar si se realizó o no obligación la verificación de la veracidad de lo expuesto en la declaración.

Así, la Sala se pronunció en sentencia con ponencia del Dr. José María Esguerra Samper ${ }^{33}$, indicando que estando probadas reticencias o inexactitudes de parte del tomador del seguro en el cuestionario que le sometió la Compañía demandada, cabía decretar la nulidad relativa de la póliza de incendio, porque la ley no le imponía a dicha compañía el deber especifico de verificar tales inexactitudes o de suplir las reticen-

$31 \quad$ Oportunidad en la cual la SFC señaló: "Esto, con prescindencia de extemporáneas consideraciones sobre la necesidad de que la reticencia o inexactitud tenga relación de causalidad con el siniestro que haya podido sobrevenir, justamente porque lo que se pretende es restablecer o tutelar un equilibrio contractual roto ab initio, en el momento de celebrar el contrato de seguro, y no al acaecer el siniestro. La relación causal que importa y que, para estos efectos, debe existir, no es, como sostienen los demandantes, la que enlaza la circunstancia riesgosa omitida o alterada con la génesis del siniestro, sino la que ata el error o el dolo con el consentimiento del asegurador." (Subrayado fuera de texto).

32 Póliza de seguro de vida en la cual se elevó reclamación contra la aseguradora en virtud de la muerte violenta sufrida por el asegurado. La compañía decidió objetar en virtud a un comportamiento reticente en la declaración de asegurabilidad al no manifestar el padecimiento de asma en cabeza del mencionado asegurado.

33 Corte Suprema de Justicia. Sala de Casación Civil. Sentencia de 27 de julio de 1976. M.P. José María Esguerra Samper. 
cias, en que hubiera podido incurrir, dando a entender que la compañía de seguros no tiene el deber legal de contrastar la información recibida con la realidad, y, por ende, la defensa del declarante no puede basarse en este argumento. (Subrayado fuera de texto).

Asimismo, esta corporación, siguiendo con esta tesis, resaltó en sentencia con ponencia del magistrado Álvaro García Restrepo ${ }^{34}$ que la aseguradora no tiene el deber, sino la facultad, de confirmar los datos que con ese fin aquél le suministre; y que, por lo mismo, la conducta de buena fe que la respectiva empresa asuma, no sirve para evitar que se produzcan los efectos que el legislador previó para la reticencia del asegurado, en particular, la nulidad relativa del respectivo contrato de seguro. Lo anterior con base en el principio de ubérrima buena fe, cuyo contenido debe irradiar de todo contrato de seguro por sus especiales características. (Subrayado fuera de texto).

Por otro lado, esta misma corporación se pronunció en sentencia de $2002^{35}$ argumentando que si bien no existe una obligación que sea impuesta por ley al asegurador para que éste verifique la información que le sea dada en virtud de la celebración de un contrato de seguro, en el marco de una declaración de asegurabilidad, existen casos en que debe revisarse la actitud de éste, toda vez que su calidad de profesional en el campo le obliga a tener un cierto deber de cuidado en cada caso específico. Así las cosas, traslada al juzgador el cargo de determinar, en cada caso, cual debió haber sido la posición tomada por la compañía respecto al deber de verificación acá expuesto.

En este sentido, dicho deber nace de un comportamiento sospechoso por parte del declarante, que genere desconfianza al asegurador, lo cual es explicado en la sentencia en el siguiente sentido: esta reticencia (...)debió conducir a que el Tribunal declarara la nulidad relativa del contrato de seguro, sobre todo porque del acervo probatorio recaudado aflora que la compañía de seguros no tenía motivo alguno que le generara desconfianza y le impusiera el deber profesional de auscultar el estado del riesgo aún más de lo que hizo, que fue examinar el estado de salud del futuro asegurado y exigir el concepto profesional del asesor y del gerente de la agencia o sucursal de la aseguradora, víctima por tanto de un engaño que le asaltó su buena fe. (Subrayado fuera de texto).

34 Corte Suprema de Justicia. Sala de Casación Civil. Sentencia de 16 de diciembre de 2016. M.P. Álvaro García Restrepo.

35 Corte Suprema de Justicia. Sala de Casación Civil. Sentencia de 11 de abril de 2002. M.P. Jorge Santos Ballesteros. 
De lo precedente es destacable que para la Sala no existe una obligación en cabeza del asegurador de verificar la veracidad de lo aportado en la declaración del estado del riesgo, y, por lo tanto, no es procedente pretender sanear una reticencia o inexactitud con base en este argumento. Por el contrario, el contrato se entiende viciado siempre que haya reticencia, independiente de la observancia de lo aportado por parte de la compañía.

Al respecto, la SFC se ha pronunciado en diversos fallos cuyo núcleo esencial ha radicado en la no obligatoriedad en cabeza del asegurador de verificar la información aportada por el declarante.

Lo anterior se ve reflejado en distintos apartados de sentencias proferidas en cumplimiento de las funciones jurisdiccionales a su cargo, en donde se ha indicado, citando la sentencia C-232 de 1997, proferida por la Corte Constitucional, que no es exigible a la aseguradora la revisión detallada de los elementos que constituyen el riesgo, dada la celeridad de la práctica en que se desenvuelve el negocio aseguraticio (2014-0634). Esta posición es igualmente observada en sentencias de los procesos con radicados 2013-0542 y 2013-0545, cuya ratio decidendi gira en torno a la imposibilidad de imponer una obligación como la acá discutida, puesto que la práctica aseguraticia se lleva a cabo a velocidades que no permiten un examen detallado de todos y cada uno de los contratos celebrados y su contenido.

A su vez, en sentencia del proceso radicado número 2015-0819, se destaca el principio de ubérrima buena fe que permea a los contratos de seguro, asumiendo que el mismo debe respetarse sobre todo. Por ende, es deber del tomador, o asegurado (en seguros de vida), declarar sinceramente y sin omisiones la información solicitada. De tal forma, traslada al declarante la responsabilidad inexcusable de contestar lo que se le requiera, de acuerdo con la realidad. Eliminando, de esta manera, cualquier responsabilidad de observancia por parte del asegurador, ya que, de suponerse que la información suministrada es sincera, no sería viable entrar a determinar su fiabilidad.

Con base en lo observado anteriormente, es dable deducir que no hay variaciones en las posiciones encontradas en una y otra corporación. Esto es, las dos mantienen el mismo criterio frente al problema expuesto, y justifican sus decisiones basadas en los mismos argumentos, estos son, la celeridad que conlleva la práctica aseguraticia, y la ubérrima buena fe con la que debe actuar el declarante del estado del riesgo. 


\section{ALCANCES DEL DEBER DE INFORMACIÓN POR PAR- TE DEL ASEGURADOR AL TOMADOR/ASEGURADO RES- PECTO DE LA DECLARACIÓN DEL ESTADO DEL RIESGO}

En este capítulo, se procederá a estudiar lo relacionado con el deber de información del asegurador frente a quien declarará sobre el estado del riesgo, y, por lo tanto, se evaluarán las consecuencias jurídicas derivadas del deber de información que tiene la aseguradora frente a sus futuros tomadores o asegurados durante la fase previa a la celebración del contrato de seguro en los casos en que se presenta reticencia e inexactitud.

En ese sentido, tal como lo indica Andrés ORDONEZZ ${ }^{36}$, que el deber de información en el contrato de seguro es de carácter reciproco, lo cual se traduce en que, sobre el asegurador pesa el deber de informar al potencial tomador -en la etapa precontractual- el alcance de las coberturas, poner en conocimiento los condicionamientos de las coberturas, informar sobre la aplicación del infraseguro o sobreseguro en los seguros de daños, dar a conocer el alcance de las consecuencias derivadas de la declaración del estado del riesgo, con miras a prevenir reticencias o inexactitudes, entre otras manifestaciones del mencionado deber.

Frente a este punto, la Sala Civil de la $\mathrm{CSJ}^{37}$ señaló que si el tomador, a su vez, está en condiciones de conocer la información, dada su propia especialidad y el mundo de los negocios en que gira, la obligación de informar por parte de la aseguradora se morigera y queda reducida a aspectos eminentemente técnicos.

De lo anterior, se observa que, dependiendo de las características de la contraparte de la aseguradora dentro del contrato de seguro, se entenderá si la obligación de informar por parte de la aseguradora a este último se mantiene, o, por el contrario, disminuye.

Esto es tratado desde el punto de vista de la SFC, frente al especifico punto de las reticencias e inexactitudes cuando en sentencia del proceso 2014-0419 ${ }^{38}$ señaló que la declaración de incumplimiento del deber de información al momento de suscribir el cuestionario de asegurabilidad,

36 ORDOÑEZ, A. O. (2012). Estudios de Seguros (Primera ed.). Bogotá, Colombia: Universidad Externado.

37 Corte Suprema de Justicia. Sala de Casación Civil. Sentencia de 19 de mayo de 1999. M.P. José Fernando Ramírez.

38 Póliza de seguro de vida de deudores, que pretendía ser afectada por parte de la asegurada a raíz de una incapacidad total y permanente. Sin embargo, la compañía objetó en virtud a una reticencia derivada de la no declaración de hipertensión anterior a la declaración de asegurabilidad. 
en un seguro grupo vida deudores, no es suficiente para excluir de responsabilidad al asegurado por reticencia.

No obstante, dicha determinación obedeció que "la declaración surtida por la activa respecto de haber sido inducida a firmar la declaración de asegurabilidad sin información u orientación alguna no encuentra soporte en otros medios probatorios, por el contrario, obran en el plenario las tantas veces citadas solicitudes de certificado individual, que expresamente reconoció haber firmado e impuesto en ellas su huella dactilar.

Con respecto a las sentencias dictadas por la corporación en cuestión, en procesos 2014-0409 y 2015-0963, se infiere que la sola afirmación del asegurado de no haber sido informado sobre la firma del cuestionario de asegurabilidad, no exonera a la parte asegurada de sustraerse a los efectos que la declaración de nulidad relativa comporta, salvo que se acredite en forma fehaciente alguna negligencia atribuida al asegurador en este sentido.

Es decir, el hecho de que en un cuestionario de asegurabilidad se consigne en caracteres destacados que el declarante no debe firmar sin verificar el texto a suscribir es suficiente para probar la culpa del tomador. No obstante, esta podría ser desvirtuada con una prueba en la que se demuestre que este último fue inducido a firmar sin leer el contenido de la declaración de asegurabilidad o el formulario correspondiente.

Sin perder de vista lo anterior, la doctrina, encabezada por Andrés ORDOÑEZ $^{39}$, se ha pronunciado frente a la responsabilidad derivada de la intervención de los intermediarios de seguros, principalmente, las agencias. Esto, puesto que podría llegar a considerarse que dicha intervención puede dar lugar a reticencias e inexactitudes, pero que, debido al entramado normativo existente es difícil determinar hasta qué punto puede o no la representación que ejerce la agencia limitar la responsabilidad del asegurado cuando éste ha sido reticente o inexacto en su declaración.

Así pues, al no existir un sistema normativo claro y expreso en esta materia, se da lugar a un entendimiento amplio de la responsabilidad $\mathrm{y}$ de las funciones que tiene en su cabeza el intermediario; lo cual produce que en ocasiones, un actuar de mala fe por parte de la agencia frente al asegurador en situaciones como el insuficiente asesoramiento al tomador sobre la manera en que debe diligenciarse la declaración de asegurabilidad o el ocultamiento al asegurador de circunstancias que se lleguen a conocer respecto del estado del riesgo, pueden trasladar

39 ORDÓÑEZ, A. (2005). El tratamiento civil de la mala fe del asegurado en el contrato de seguro. Revista Mercatoria. 
responsabilidad a la compañía, y, por lo tanto, cerrarle las puertas a una posible defensa proveniente de una reticencia o inexactitud del tomador/asegurado.

Por ende, dependiendo de las circunstancias precisas de cada caso se debe entrar a determinar la responsabilidad del intermediario y su eventual traslado al asegurador, de las situaciones que podrían configurar o no una reticencia o inexactitud que desemboque en la nulidad relativa del contrato de seguro.

\section{ACTOS QUE COMPORTAN DECLARACIONES INEXAC- TAS Y/O RETICENTES}

En el presente capitulo se abordará, de manera general, distintas conductas de los tomadores o asegurados que se traducen en declaraciones inexactas y/o reticentes y, por consiguiente, tienen la virtualidad de anular el contrato de seguro con las consecuencias que ello comporta.

Para empezar, la Corte ${ }^{40}$ consideró como reticencia la declaración falsa del asegurado sobre su posición laboral e ingresos en el momento de tomar un seguro de vida, afirmando que al tomador del seguro incumbe la carga precontractual de declarar sinceramente el estado del riesgo, es decir, aquellos hechos o circunstancias de significación que le permiten al asegurador sopesar la potencial siniestralidad en relación con el evento incierto materia del contrato, de modo que, conociéndola casi siempre por las informaciones del tomador, opte por asumir el riesgo y así tasar adecuadamente la prima o desistir de la celebración del contrato de seguro.

Por ende, se deduce que una declaración inexacta es aquella que no es congruente con la realidad, y no permite tasar la prima de manera correcta -en atención al riesgo asumido por el Asegurador- y, por consiguiente, falsea el consentimiento del Asegurador. A su turno, la reticencia comporta el ocultamiento o el silencio del declarante.

Por su parte, la SFC en providencia dictada en proceso 2012-0035 destacó que cuando la compañía aseguradora incurre en error inducido por el asegurado, hay lugar a declarar la nulidad relativa del contrato por reticencia. Lo cual es a todas luces congruente con la sentencia antes citada, puesto que estos errores a los que induce el declarante con la

$40 \quad$ Corte Suprema de Justicia. Sala de Casación Civil. Sentencia de 11 de abril de 2002. M.P. Jorge Santos Ballesteros. 
información falsa o inexacta propuesta, conllevan a una alteración en la estimación del riesgo, y, por lo tanto, en la tasación de la prima, lo cual deja vulnerable a la aseguradora al no contar con todos los elementos necesarios para encuadrar el riesgo dentro de los de su especie, y calcular así su real probabilidad de ocurrencia.

Así las cosas, es dable concluir que los actos que constituyen reticencia o inexactitud no pueden ser limitados taxativamente, sino que, por el contrario, son innumerables y pueden predicarse en el contexto de cualquier clase de seguro y comprende infinidad de circunstancias.

\section{LA CARGA DE LA PRUEBA DE LA MALA FE EN CASOS DE RETICENCIA E INEXACTITUD}

En lo que concierne a este aspecto, la SFC señaló en sentencia dentro de proceso 2015-0725 que es deber de la aseguradora probar la mala fe en los casos de preexistencia ${ }^{41}$ y reticencia en el contrato de seguro. Lo anterior con miras a imponer la sanción que prevé el C.Co. para este tipo de casos. Así, al alegarse de reticencia, se le impone al asegurador la carga de probar el conocimiento previo del asegurado y la mala fe con la que éste obró frente a su contraparte.

En efecto, la SFC en sentencia de proceso 2015-1148 falló en igual sentido, reconociendo que es deber del asegurador, al momento de alegar la reticencia, probar la mala fe con la que actuó su tomador o asegurado en la declaración de asegurabilidad, con miras a imponer las sanciones previstas en la ley comercial. Esto, apoyado en sentencia de tutela de la Corte Constitucional ${ }^{42}$, cuya tesis central indica lo reproducido por la SFC en los casos expuestos.

Sin embargo, respecto a este último fallo es relevante mencionar que es cuestionable el hecho que se aplique una sentencia de tutela, cuyos efectos son inter partes, para justificar una decisión de una controversia cuyos sustratos fácticos son disímiles. Sin embargo, esta es una tendencia que parece abrirse camino en los pronunciamientos de la Delegatura.

41 Al respecto, en sentencia T-670 de 2016 de la Corte Constitucional, con ponencia del magistrado Jorge Iván Palacio, se destacó la diferencia existente entre preexistencia y reticencia, según la cual, la última exige mala fe para concretarse, mientras que la primera es un hecho objetivo. Por lo tanto, a la aseguradora que pretenda alegar nulidad relativa del contrato en virtud de una reticencia, no le será suficiente probar una preexistencia, sino que, además, deberá acreditar la mala fe.

42 Corte Constitucional. Sentencia T-222 de 2014. M.P. Luis Ernesto Vargas Silva. 


\section{CONCLUSIÓN}

En conclusión, es observable, de lo expuesto anteriormente, que, tanto la Corte Suprema de Justicia-Sala de Casación Civil, como la Delegatura para Funciones Jurisdiccionales de la Superintendencia Financiera, han establecido, con el paso del tiempo, líneas decisionales similares, en materia de reticencias e inexactitudes dentro del Contrato de Seguro, las cuales no se han distanciado, sino que, por el contrario, han mantenido un mismo sentido y cuerpo argumentativo, lo cual, en aras de garantizar la seguridad jurídica, es sumamente gratificante.

Además, a lo anterior, se encuentra que la Delegatura, como juez de instancia que es, ha respetado los patrones jurisprudenciales establecidos por la Corte Suprema, y ha conducido sus decisiones en el camino que esta última ha marcado, lo cual es comprobable al evidenciar que, las providencias del mencionado juez especializado, suelen citar a la CSJ y la Corte Constitucional.

Así las cosas, se encuentra que el balance que arroja la entrada en vigor de las facultades jurisdiccionales de la Superintendencia Financiera, dentro de lo relativo al contrato de seguro, y más específicamente a lo relacionado con las reticencias o inexactitudes, denota un desarrollo detallado de cada una de las temáticas y situaciones presentadas, y una correcta y uniforme aplicación de los criterios jurisprudenciales establecidos por las altas cortes, en paralelo con un estudio correspondiente a un juez especializado en la materia.

\section{BIBLIOGRAFÍA}

Corte Suprema de Justicia. Sala de Casación Civil. Sentencia de 19 de mayo de 1999. M.P. José Fernando Ramírez.

Corte Suprema de Justicia. Sala de Casación Civil. Sentencia de 18 de octubre de 1995. M.P. Pedro Lafont Pianetta.

Corte Suprema de Justicia. Sala de Casación Civil. Sentencia de 14 de julio de 2006. M.P. Silvio Fernando Trejos.

Corte Suprema de Justicia. Sala de Casación Civil. Sentencia de 1 de junio de 2007. M.P. Ruth Marina Díaz Rueda.

Corte Suprema de Justicia. Sala de Casación Civil. Sentencia de 16 de diciembre de 2016. M.P. Alvaro García Restrepo. 
Corte Suprema de Justicia. Sala de Casación Civil. Sentencia de 27 de julio de 1976. M.P. José María Esguerra Samper.

Corte Suprema de Justicia. Sala de Casación Civil. Sentencia de 2 de agosto de 2001. M.P. Carlos Ignacio Jaramillo.

Corte Suprema de Justicia. Sala de Casación Civil. Sentencia de 24 de octubre de 2005. M.P. Silvio Fernando Trejos.

Corte Suprema de Justicia. Sala de Casación Civil. Sentencia de 30 de noviembre de 2000. M.P. Jorge Castillo Rugeles.

ORDÓÑEZ, A. (2005). El tratamiento civil de la mala fe del asegurado en el contrato de seguro. Revista Mercatoria.

ORDOÑEZ, A. (2012). Estudios de Seguros (Primera ed.). Bogotá, Colombia: Universidad Externado.

Superintendencia Financiera de Colombia. Delegatura para Funciones Jurisdiccionales. Sentencia de 10 de abril de 2014. Rad. 2013-0545.

Superintendencia Financiera de Colombia. Delegatura para Funciones Jurisdiccionales. Sentencia de 21 de abril de 2014. Rad. 2013-0542.

Superintendencia Financiera de Colombia. Delegatura para Funciones Jurisdiccionales. Sentencia de 28 de enero de 2014. Rad. 2013-0345.

Superintendencia Financiera de Colombia. Delegatura para Funciones Jurisdiccionales. Sentencia de 14 de noviembre de 2014. Rad.2014-0221.

Superintendencia Financiera de Colombia. Delegatura para Funciones Jurisdiccionales. Sentencia de 27 de junio de 2013. Radicado 2012-0035

Superintendencia Financiera de Colombia. Delegatura para Funciones Jurisdiccionales. Sentencia de 9 de enero de 2015.Radicado 2014-0698.

Superintendencia Financiera de Colombia. Delegatura para Funciones Jurisdiccionales. Sentencia de 30 de abril de 2014. Radicado 2013-0662.

Superintendencia Financiera de Colombia. Delegatura para Funciones Jurisdiccionales. Sentencia de 24 de enero de 2014- Radicado 2013-0333.

Superintendencia Financiera de Colombia. Delegatura para Funciones Jurisdiccionales. Sentencia de 11 de junio de 2014. Radicado 2013-0800.

Superintendencia Financiera de Colombia. Delegatura para Funciones Jurisdiccionales. Sentencia de 17 de enero de 2014. Radicado 2013-0372. 
TORRES, J. F. (2003). Deberes de información en la etapa pre-contractual a cargo del asegurado y candidato a tomador. Revista Ibero-Latinoamericana de Seguros.

Corte Constitucional. Sentencia C-232. M.P. Jorge Arango Mejía.

Corte Constitucional. Sentencia T-153 de 2014. M.P. Mauricio González Cuervo.

Corte Constitucional. Sentencia T-222 de 2014. M.P. Luis Ernesto Vargas Silva. 
